\title{
Hemobilia: another complication associated with anti-thrombotic therapy
}

\section{$\operatorname{AUTHOR}(\mathrm{S}):$}

Hiramatsu, Yukiko; Watanabe, Tomohiro;

Shiokawa, Masahiro; Kurita, Akira; Matsuura, Minoru; Uza, Norimitsu; Kodama, Yuzo; Chiba, Tsutomu

\section{CITATION:}

Hiramatsu, Yukiko ... [et al]. Hemobilia: another complication associated with antithrombotic therapy. Clinical Journal of Gastroenterology 2011, 4(1): 49-51

\section{ISSUE DATE:}

2011-02

URL:

http://hdl.handle.net/2433/139611

\section{RIGHT:}

The final publication is available at www.springerlink.com; This is not the published version. Please cite only the published version.; この論文 は出版社版でありません。引用の際には出版社版をご確認ご利用くだ さい。 


\section{Hemobilia: Another Complication Associated with Anti-thrombotic Therapy}

Yukiko Hiramatsu MD, Tomohiro Watanabe MD, PhD, Masahiro Shiokawa MD, Akira Kurita MD, Minoru Matsuura MD, PhD, Norimitsu Uza MD, Yuzo Kodama MD, PhD, and Tsutomu Chiba MD, PhD.

Department of Gastroenterology and Hepatology, Kyoto University Graduate School of Medicine

Address correspondence to: Tomohiro Watanabe MD, PhD,

Department of Gastroenterology and Hepatology,

Kyoto University Graduate School of Medicine,

54 Shogoin Kawahara-cho, Sakyo-ku, Kyoto 606-8507, Japan.

E-mail: tmhrwtnb@kuhp.kyoto-u.ac.jp

Phone: 81-75-751-4319

Fax: 81-75-751-4303

Running Title: Hemobilia associated with anti-thrombotic therapy

Key Words: Hemobilia, anti-thrombotic therapy, liver abscess 


\section{Abstract}

It is generally accepted that anti-thrombotic therapy increases the risk of gastrointestinal bleeding and concurrent therapy with a proton-pump inhibitor is a standard treatment for patients receiving aspirin. Thus, much attention has been paid to the prevention of gastrointestinal bleeding in such patients. However, it should be noted that patients treated with anti-thrombotic therapy always carry a risk of hemorrhage from any organs including the gastrointestinal tract. Here, we present a case with formation of a common bile duct stone caused by hemobilia associated with anti-thrombotic therapy. This case suggests that we need to bear in mind a possibility of intrabiliary hemorrhage as well as gastrointestinal bleeding in patients receiving anti-thrombotic therapy. Patients with the former complication show a variety of symptoms associated with liver abscess, cholangitis, pancreatitis, and duodenal bleeding. 


\section{Introduction}

Anti-thrombotic therapy is widely used for the prevention of heart attack and stroke $[12,3]$. Patients treated with anti-coagulant and/or anti-platelet drugs sometimes suffer from gastrointestinal bleeding. Thus, anti-thrombotic therapy increases the risk of upper gastrointestinal bleeding and much attention has been paid to the prevention of gastrointestinal bleeding associated with ant-thrombotic therapy $[1,2,3]$. However, it should be noted that patients treated with such therapy always carry a risk of hemorrhage from any organs including the gastrointestinal tract. Hemobilia, which is defined as hemorrhage into the biliary tract, causes a variety of symptoms associated with gastrointestinal bleeding, liver abscess, cholangitis, and obstructive jaundice [4-6]. Causes of hemobilia include trauma, gallstones, aneurysma, tumor, and coaguloptahy [4, 5]. Although spontaneous hemobilia may, like upper gastrointestinal bleeding, be caused by administration of anti-coagulant or anti-platelet drugs, little attention has been paid to the risk of hemobilia in patients treated with anti-thrombotic drugs. Here, we present a case with formation of a common bile duct (CBD) stone caused by hemobilia associated with anti-thrombotic therapy.

\section{Case Report}

A 58-year-old man with a history of acute myocardial infarction (AMI) and diabetes mellitus presented to our hospital with fever and general fatigue. Blood examination revealed leukocytosis (11400 cells/mm3) and an elevated level of serum C-reactive protein $(26.2 \mathrm{mg} / \mathrm{dL}$; normal level<0.5). His serum hepatobiliary enzyme levels were also elevated (aspartate aminotransferase 53 IU/L; normal 13-33, alkaline phosphatase $461 \mathrm{IU} / \mathrm{L} ; 129-241$, $\gamma$-glutamyl transpeptidase $187 \mathrm{IU} / \mathrm{L} ; 9-54)$. Escherichia coli was detected in his blood. Abdominal contrast-enhanced computed tomography, which was performed to detect the origin of the infection, revealed a tumor in segment 8 of the liver (Fig. 1) and a dilated CBD. The liver tumor consisted of a central hypo-dense area and peripheral areas with ring-like enhancements; these findings were consistent with those of pyogenic hepatic abscess [7]. Endoscopic 
ultrasonography (EUS) and magnetic resonance cholangiopancreatography (MRCP) revealed the presence of a narrow substance without acoustic shadowing at the bottom of the dilated CBD (Fig. 2A, B). This finding strongly suggested that the normal flow of bile was abrogated by the debris or stone in the CBD. Based on these data, the patient was diagnosed as septicemia due to liver abscess associated with debris or stone in the CBD. Although the patient had no history of gallbladder disease, EUS and MRCP revealed segmental wall thickening of fundal and body portions of the gallbladder, suggesting the presence of segmental and fundal type adenomyomatosis. The filling defect in the CBD was also detected using endoscopic retrograde cholangiography and a narrow-long fragile stone with dark brown color was endoscopically removed (Fig. 2C). The liver abscess resolved soon after the removal of the CBD stone, which suggested that this CBD stone was responsible for the liver abscess development.

Since the shape and color of this stone were different from those of the typical cholesterol and pigment stones, we analyzed this stone by using infrared absorption spectroscopy. Surprisingly, infrared absorption spectroscopy revealed that a major component (>98\%) of this stone was protein. The fact that this patient had been treated with anti-thrombotic therapy including systemic heparinization, after AMI, which occurred 6 months before admission led us to consider the possibility that clots originating from an intrabiliary hemorrhage caused by anti-thrombotic therapy became compact with increasing bile content to inhibit the normal bile flow. To verify this idea, we tried to detect the presence of serum proteins such as $\mathrm{IgG}$ in the protein extracts from this stone. We performed electrophoresis and immuno-blotting as described previously [8]. The presence of IgG light chain was confirmed by Coomassie blue staining of the blotted membrane when $56 \mu \mathrm{g}$ of isolated proteins was applied to the gel (Fig. 3A). More importantly, immuno-blotting by using anti-human IgG antibody revealed the presence of both heavy and light IgG chains (Fig. 3B). Considering that gallstones usually do not contain a significant amount of human IgG, it is strongly suggested that the detected IgG originated from serum and that intraluminal clots caused by hemobilia became compact with increasing bile 
content.

\section{Discussion}

Upper gastrointestinal bleeding is often seen in patients treated by anti-thrombotic therapy $[1,2,3]$. In contrast, anti-thrombotic therapy causes intrabiliary hemorrhage in a very limited number of patients. Thus, it is likely that there is a trigger for the development of hemobilia in such patients. Such potential triggers include biliary inflammation and invasion of cancer cells into the biliary tract [4-6]. In this regard, spontaneous hemobilia is sometimes caused by overdoses of anti-platelet and/or coagulant drugs [5], which suggests the involvement of decreased coagulability in the development of hemobilia. Indeed, this patient had been treated with anti-thrombotic therapy including systemic heparinization. Further clinical analysis is required to determine the factors that increase the risk of intrabiliary hemorrhage in such patients.

An important finding from this case is that clots that remain in the bile duct may serve as a nidus for gallstone formation. We have proved that proteins isolated from the narrow substance in CBD contain a significant amount of IgG derived from serum. Thus, it is likely that the CBD substance causing liver abscess and dilatation of the bile duct originates from clots in this case. Therefore, formation of gallstone may be one of the late complications of hemobilia. Although acute biliary obstruction by clots sometimes causes fever, epigastralgia, and jaundice due to cholangitis, cholecystitis and pancreatitis at the onset of hemobilia $[4,5]$, similar symptoms can occur at a late phase as a result of stone formation. This idea is supported by the report on 2 cases of biliary calculi caused by hemobilia [9]. Given the fact that serum levels of $\gamma$-glutamyl transpeptidase in this case were elevated from two months before the admission, we speculate that clots in the bile duct had existed for more than two months in this case.

In conclusion, antithrombotic therapy may increase the risk of hepatobiliary diseases by causing hemobilia. We need to bear in mind a possibility of hemobilia as well as gastrointestinal bleeding in patients receiving 
anti-thrombotic therapy.

\section{Acknowledgements}

This study is supported in part by the grant from the Shimizu Foundation for Immunology Research.

\section{Figure legends}

Figure 1. Abdominal computed tomography image showing the development of liver abscess in segment 8 (arrows).

Figure 2. (A) Magnetic resonance cholangiopancreatography image showing a narrow and long substance (arrows) at the bottom of the common bile duct (CBD). (B) Endoscopic ultrasonography image showing a narrow substance without acoustic shadowing at the bottom of the dilated CBD (arrows). (C) Endoscopic removal of a narrow-long fragile stone with dark brown color.

Figure 3. Protein extracts $(14,28,56 \mu \mathrm{g})$ isolated from the CBD stone was subjected to Coomassie blue staining $(A)$ and immuno-blotting with anti-human lgG antibody (B). $\quad{ }^{* *} \lg G$ heavy chain; * ${ }^{* * *} \lg G$ light chain. 


\section{References}

1. Derry S, Loke YK. Risk of gastrointestinal haemorrhage with long term use of aspirin: meta-analysis. BMJ 2000;321:1183-7.

2. Lai KC, Lam SK, Chu KM, Wong BC, Hui WM, Hu WH, et al. Lansoprazole for the prevention of recurrences of ulcer complications from long-term low-dose aspirin use. N Engl J Med 2002;346:2033-8.

3. Lanas A, Bajador E, Serrano P, Fuentes J, Carreno S, Guardia J, et al. Nitrovasodilators, low-dose aspirin, other nonsteroidal antiinflammatory drugs, and the risk of upper gastrointestinal bleeding. $\mathrm{N}$ Engl $\mathrm{J}$ Med 2000;343:834-9.

4. Green MH, Duell RM, Johnson CD, Jamieson NV. Haemobilia. Br J Surg 2001;88:773-86.

5. Sandblom P. latrogenic hemobilia. Am J Surg 1986;151:754-8.

6. Bloechle C, Izbicki JR, Rashed MY, el-Sefi T, Hosch SB, Knoefel WT, et al. Hemobilia: presentation, diagnosis, and management. Am J Gastroenterol 1994;89:1537-40.

7. Gabata T, Kadoya M, Matsui O, Kobayashi T, Kawamori Y, Sanada J, et al. Dynamic CT of hepatic abscesses: significance of transient segmental enhancement. AJR Am J Roentgenol 2001;176:675-9.

8. Watanabe T, Asano N, Fichtner-Feigl S, Gorelick PL, Tsuji Y, Matsumoto Y, et al. NOD1 contributes to mouse host defense against Helicobacter pylori via induction of type I IFN and activation of the ISGF3 signaling pathway. J Clin Invest 2010;120:1645-62.

9. Luzuy F, Reinberg O, Kauszlaric D, Anderegg A, Droguett M, Donati D, et al. Biliary calculi caused by hemobilia. Surgery 1987;102:886-9. 